\title{
Relation-Making to Sense-Making: Supporting College Students' Constructive Understanding with an Enriched Collaborative Note-Sharing System
}

\author{
Naomi Miyake \& Hiroyuki Masukawa \\ School of Computer and Cognitive Sciences, Chukyo University, Toyota, 470-0393, Japan \\ Tel: 81-565-45-0971, Fax: 81-565-46-1296 \\ Email: nmiyake@ sccs.chukyo-u.ac.jp, masukawa@grad.sccs.chukyo-u.ac.jp
}

\begin{abstract}
We report here a case of university level collaborative learning supported by a notesharing system called Reflective Collaboration Note or ReCoNote. The system is enriched with the mutual linking capability that requires the learners to explicitly think about and comment on relationships between two pieces of information. In a course on human problem solving the students first studied and reported some classical problem solving literature. The students are then asked to make relations among their presentations by utilizing ReCoNote's mutual linking function, and report to the class the linkages they made. In the third phase, a report on the characteristics of humans as problem-solving systems was required as the summary activity. The log data analyses reveal that the students visited other groups' notes often and as the course develops, links spread from within one's own group's notes to cover notes created by other members belonging to other study topics. Students who actively used the system tended to turn in high-quality summaries. The system has been used in three half-year classes and the initial analyses of the activities have revealed that this mutual linking did in fact help the learners learn rather complicated topics in cognitive science.
\end{abstract}

Keywords: cognitive science, higher education, learning environments, reflection

\section{Introduction}

We report here a case of university level collaborative learning supported by a note-sharing system enriched with the mutual linking capability. "Mutual linking" refers to the system's feature that requires the learners to explicitly think about the relationships among the learning materials from two different perspectives, from A to B first and then from B to A. When these bi-directional links are accumulated, the whole class is encouraged to collaboratively scrutinize the links. Through this activity each individual student is expected to construct her/his own conceptual understanding of the learning materials, to grasp the whole range of the topic to be learned. The system has been used in three half-year classes and the initial analyses of the activities have revealed that this mutual linking did in fact help the learners learn rather complicated topics in cognitive science.

When a teacher organizes a series of classroom activities around a theme, very often her overall structure is not explicitly delivered to the class, because it is not always regarded as necessary. Interviewing students reveals that such hidden organizations are not necessarily shared or understood by the students. Project-based learning is known to lead students to start seeing such structures at the college level education, but separated projects can limit the scope of coverage for each individual student to deal with in a limited amount of the course time. Mutual linking and collaborative scrutinization of the links are the methods we propose to improve these situations.

The fundamental guidelines in designing collaborative learning activities for our practice are based on the idea of constructive interaction, which claims that collaboration, when developed constructively, can help participating individuals deepen their conceptual understandings (Miyake, 1986). In order for collaboration to develop constructively, each participant should be given chances to externalize her/his intermediate products of cognitive activities like thinking and problem solving (Shirouzu \& Miyake, 1999; Kirsh \& Maglio, 1994), and to reflect upon such externalized objects (Miyake, 1996). It is then necessary that the classroom activities be designed to provide students with chances to externalize and reflect. 
A technology like a shared note taking can support collaborative externalization and reflection in this sense. CSILE may be one of the best examples in this field (Bereiter \& Scardamalia, 1993). The students should also be encouraged to reflect on their externalized notes, by solving some shared problem and by tying together the contributed pieces of their work. This relation-making activity can and should be strengthened in existing notesharing systems (Bell, et al., 1995). In our practice, with the above described mutual linking feature, the students are first explicitly encouraged to engage in deliberate relation-making among their own survey reports, the resultant links of which then becomes a target for collaborative reflection by the whole class. These dual reflective activities are hypothesized in our study to help students construct their own conceptual understandings.

\section{ReCoNote}

A collaborative learning support system called Reflective Collaboration Note or ReCoNote has been developed and applied in college level cognitive science classes for three years. It is a note-sharing system with the mutual-linking capability. It explicitly asks learners, when they hit upon two "link-able" pieces of information, to link them together with specific comments on the relationship. The link comments are stored and listed whenever the attached notes are viewed. The two pieces may be one's own notes, other's notes, group's notes or class materials provided by the teacher. The system's mutual linking feature requires the learners to take multiple perspectives on the leaning materials, by asking them to write down link comments bi-directionally, i.e., for notes A and $\mathrm{B}$, from $\mathrm{A}$ to $\mathrm{B}$ first and then from $\mathrm{B}$ to $\mathrm{A}$.

ReCoNote has two windows to simultaneously show two learning materials (Figure 1). The materials include student's individual notes as well as group notes, teacher-provided learning materials, and announcements of classroom activities and of the system support. Each note comes with the accompanying "link list," which is a list of comments with author names of links that tie the information in the adjacent window to some other piece of information in the entire note system. When the comment is clicked, the linked information appears on the other window on the screen. All the information can also be summoned up onto one of the windows by going through the menu provided at the top of each note.

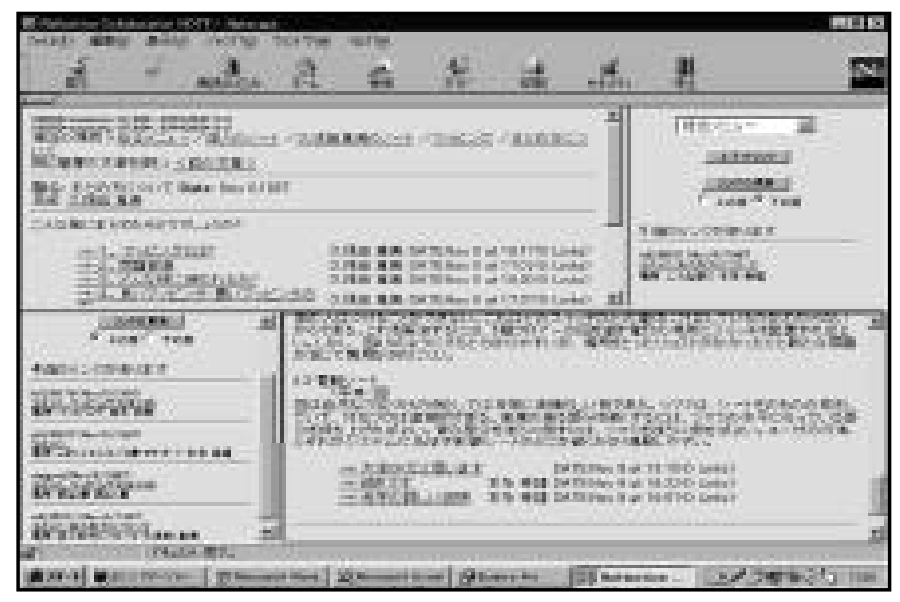

Figure1. ReCoNote windows

To write a note, click on a "make a note" button that opens up a new window. There is a separate small window to write in the note title, which appears on the menu as a list of titles. If you wish to make a link between the two notes you are currently working on (most typically this happens when a student is writing his/her own note while looking at another piece of information in the other window, such as a teacher-provided learning material or notes taken by some other students), click on "make a new link" button to open a new window, having two slots to write in comments explaining why the two pieces of information are related. There are two slots because the system explicitly asks for students to think about the directionality of the link: With notes A and B, one relation could be made from A to B while the relationship seen from B to A often requires other type of specification. 


\section{Curriculum to Support the Use of this System}

To take advantage of this support system, some collaborative learning curricula have been developed to cover cognitive science topics including cognitive engineering and problem solving. In this report we explain a specific curriculum developed to cover an upper-level, undergraduate course on problem solving. The goal of the course is to gain a general understanding of the main characteristics of humans as problem solving systems, by reviewing the relevant literature and writing a summary report on the theme.

There were three phases in the class. First was the literature review phase ("Literature study" phase). Students were grouped into small task forces according to their interests in topics widely covering the classical problem solving literature. In the first class they answered questions on classical puzzles, what they were, how to solve them, and how much literature associated with each puzzle they knew. Upon answering this set of questions they decided which puzzle they would take on as their literature research topic. Students then formed groups according to the topics. In our 1998 practice, the topics included 11 puzzles, with 25 variations: the Tower of Hanoi, the Luchins' water jar, the Polson's water jar, the river crossing problem, the Wason four-card problem, the monkey and the banana problem, Baysian statistics problems, Dunker's stomach ulcer problem, and the like. The results of the literature studies were recorded on ReCoNote with coverage of some variations of the original research. For example, on the Tower of Hanoi puzzle, students were encouraged to include explanations of the original puzzle, the difficulty human solvers generally encounter to solve its typical version (5 disks or so), the recursive structure of its solution, its role in the development of the typical information processing model of a problem-solving system like GPS in the original Simon and Newell's formulation, its variations like the adaptive production systems, and Zhang and Norman's re-formulation of its dependence on external resources.

The second phase was devoted to relation making, utilizing ReCoNote's mutual linking function ("Relation finding" phase). After three weeks preparation each group reported what they had surveyed to the class. While listening to this presentation, the "audience" students were encouraged to think about how they would relate to what is being presented with what they had researched under their title. They were then required to link the important relations among the notes on the system.

The presentation and the linking took another three weeks. The groups were then asked to report to the class the linkages they had made among all the class notes. Prior to this the teacher gave a short guiding lecture on how the pieces could be tied together, actually pointing to the possible clustering features like historical roles the puzzles played, and human characteristics each puzzle revealed. After the presentations, the teacher again gave a rather detailed one-hour lecture on the general view of the field of the research, focusing particularly on their current developments, including their expansion to everyday, collaborative types of problem solving in real-world settings, and showed how the classical research findings helped the research development.

In the third phase, students were required to write a report on the characteristics of humans as problemsolving systems as the summary activity ("Summary writing" phase). This report could either be done individually or by groups. Note that even the individual reports were in effect required to take into account the entire class activity. Thus, the report could not be done properly unless the students took a close look at what others had studied. The final reports were put onto ReCoNote so that the students could share the collaborative outcomes of the class.

\section{Results}

The general performance of the class was higher than that of classes in previous years, but no statistical tests were attempted yet. Overall, fifty-seven students used the notes with a total of 749 log-ins, and they all successfully finished the course. The students formed 23 groups, to work on 11 topics, resulting in the situation where there were often more than two groups separately working on the same topic. They created 310 notes in total, among which 114 were of individuals and 196 were group notes. Of these, 189 links were made by 32 students.

\section{Note Sharing}

Table 1 shows how many notes were actually visited by whom. 
Table 1. Number of notes visited by one's own group and other groups

\begin{tabular}{|c|c|c|c|}
\hline own groups & others' groups & cannot tell & Total \\
\hline 383 & 6924 & 491 & 7798 \\
\hline
\end{tabular}

Clearly, the students visited other groups' notes often. Among the 23 groups, 6 groups visited notes written by all the groups, and 14 groups visited notes from more than 13 groups, indicating that the created notes, whoever made them, were actively used during the course.

\section{Contents of the Notes}

Notes were categorized into seven types in order to examine what kinds of contents were written on the notes when. Content categories are:

Task......... Explains the "tasks"

Solution......Explains how to solve the task

Findings.......Explains the findings reached by studies done on the task

Terms and characteristics...Explains important terms related to the researches around the task as well as the characteristics of such research

Comments...Comments on class activities

Data..........Explains real data obtained by actually running small-scale experiments

Other

Table 2 shows which type of notes were made by whom (whether by an individual or by a group) and when (which phase of the class).

Table 2. Number of each note type made in three learning phases by individuals and groups.

\begin{tabular}{|c|c|c|c|c|c|c|c|}
\hline \multirow{2}{*}{$\begin{array}{l}\text { Phase } \\
\text { Author }\end{array}$} & \multicolumn{2}{|c|}{ Literature study } & \multicolumn{2}{|c|}{ Relation finding } & \multicolumn{2}{|c|}{ Summary writing } & \multirow{2}{*}{ Total } \\
\hline & Groups & Individuals & Groups & Individuals & Groups & Individuals & \\
\hline Task & 48 & 1 & 3 & 3 & 0 & 1 & 56 \\
\hline Solution & 34 & 3 & 2 & 0 & 0 & 1 & 40 \\
\hline Findings & 31 & 0 & 3 & 8 & 0 & 1 & 43 \\
\hline $\begin{array}{l}\text { Terms \& } \\
\text { Characteristics }\end{array}$ & 25 & 2 & 8 & 9 & 5 & 44 & 93 \\
\hline Comments & 1 & 9 & 0 & 0 & 2 & 2 & 14 \\
\hline Data & 4 & 2 & 0 & 0 & 0 & 0 & 6 \\
\hline Other & 20 & 5 & 0 & 0 & 0 & 23 & 58 \\
\hline Total & 173 & 22 & 16 & 20 & 7 & 72 & 310 \\
\hline
\end{tabular}

Table 2 shows that groups wrote notes in the literature study phase, reflecting some initial collaborative efforts made by the students. In contrast they worked more individually toward the end of the course where they spent more time writing summary reports, by tying the relevant notes together. This pattern is clearly seen on the "Terms and Characteristics" notes. Further analyses on their contents reveal that all the 25 group notes created in the literature study phase were just on a single term or characteristic, while 26 out of the 44 individual notes, or $59 \%$ of such notes created in the summary writing phase integrated two or more research findings. Furthermore 12 notes 
out of those 26 took into account more than two studies in one note, indicating that the students were actively structuring the collective efforts provided by the members of the class. The log data show that these individual notes of summary were in fact actively visited during the summary writing phase. We take this as a favorable pattern of collaboration, where individual students could learn from each other.

\section{Link Making}

As shown in Table 3, 189 links were categorized according to types of notes they linked; whether they linked notes within one's own group (own group), or notes from other groups but that also studied the same topic (same topic/other group), or notes of other groups on different topics (different topics). Three notes remained unclassifiable.

Table 3. Number of links made.

\begin{tabular}{l|rrrr}
\hline & $\begin{array}{c}\text { Literature } \\
\text { study }\end{array}$ & $\begin{array}{c}\text { Relation } \\
\text { finding }\end{array}$ & $\begin{array}{c}\text { Summary } \\
\text { writing }\end{array}$ & Total \\
\hline Within own group & 22 & 15 & 31 & 68 \\
Diff. group/Same topic & 6 & 6 & 5 & 17 \\
Different topic & 1 & 49 & 51 & 101 \\
Unclassifiable & 1 & 0 & 2 & 3 \\
\hline Total & 30 & 70 & 89 & 189 \\
\hline
\end{tabular}

As the course develops, links spread from within one's own group's notes to cover notes created by other members belonging to other study topics. This suggests that the students were actually engaged in relation-making activities, where the notes provided by the other members of the class served as building blocks to re-structure the field of the problem solving research from each student's own perspective.

Among these 189 links, 133 had comments on both directions, while 43 had one-directional comments only. Comments were used mainly to explain characteristics of the linked notes and their relationships. Sometimes, the comments became too long to be a "comment" to the link, so a whole new note was created to supply enough

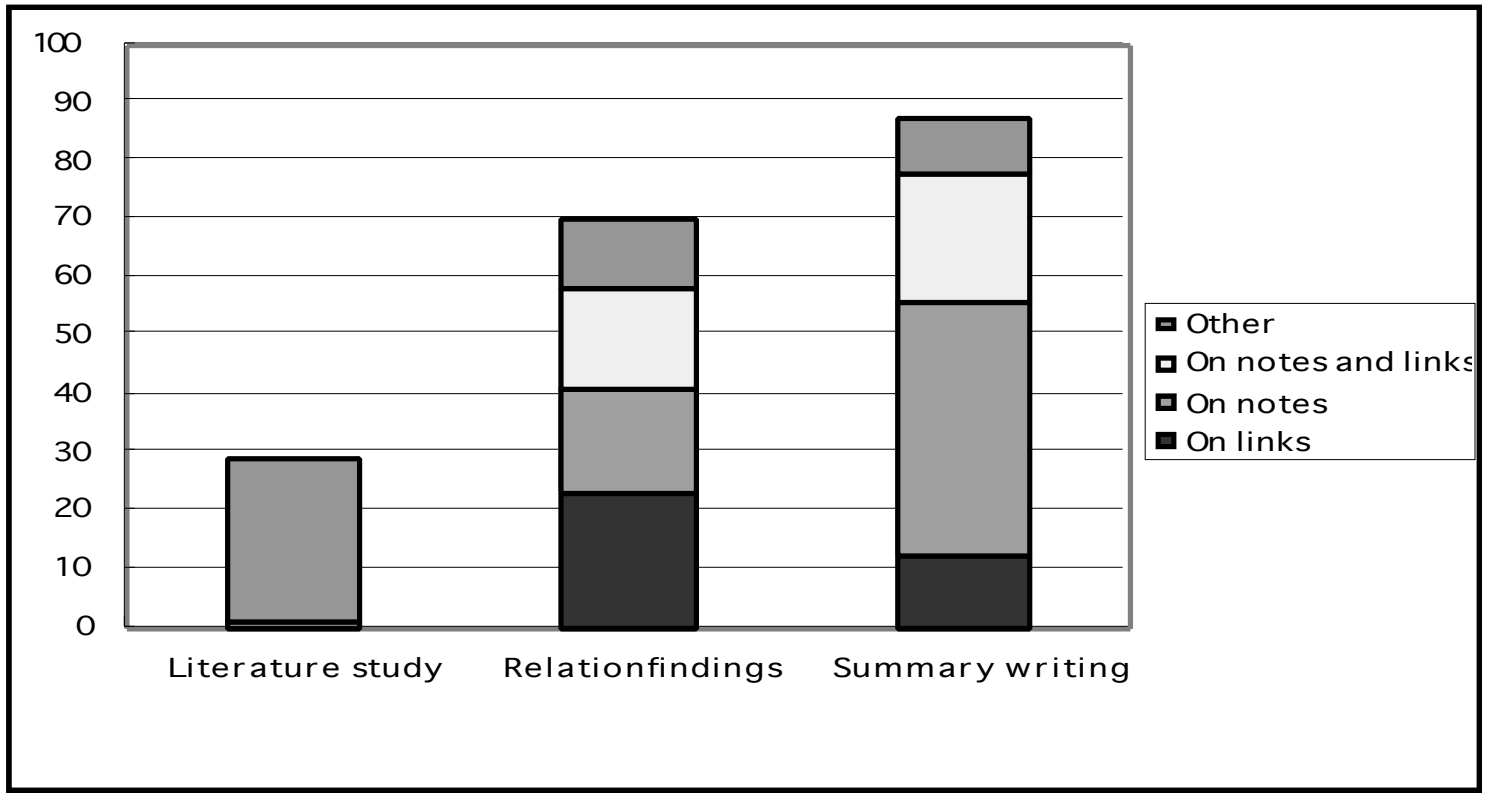

Figure 2. Where the comments were written 
writing space for the commentary, and such comment-notes were then linked together. Figure 2 shows where the comments were written: on notes and links, on linked notes, or on links only. Toward the latter part of the course, students started to use more notes to comment on; one possible explanation could simply be that they had more to say.

\section{Link Sharing}

Did links help the students read the notes? Table 4 shows how many visits a note got depending on the number of links they had.

It is clear that the more links a note had, the more chances of visits they received. Among the 15 most popular notes, 8 or $53 \%$ of them are the rich notes on research finding and terms and characteristics explanations; other 5 or $33 \%$ are "top" level notes which are the front pages to summary notes. These data suggest that the students were active in creating new ways to use the notes for their own benefits and the uses were rather quickly shared among the class members.

Table 4. Relationship between number of links and how often the notes are visited

\begin{tabular}{c|cc}
\hline No. of links & Average no. of visits & No. of notes \\
\hline $\mathbf{0}$ & 17.4 & 217 \\
$\mathbf{1}$ & 27.6 & 75 \\
$\mathbf{2}$ & 32.8 & 34 \\
$\mathbf{3 , 4}$ & 50.9 & 38 \\
$\mathbf{5 +}$ & 86.2 & 15 \\
\hline
\end{tabular}

\section{Learning Outcome}

Forty percent of the groups (10 out of 23) turned in high-quality reports on the title of "Characteristics of humans as problem solving systems." Among them, we identified three types of reports, Integrative (3 groups), Listup (4), and Self-centered (3). In integrative reports, the students covered all the materials studied by the class and yet tried to come up with an integrative view of a human being as a problem solver. They gave specific characteristics found by different research and then tried to depict a holistic view. For example, some research might characterize human beings as highly effective learners, while another report would emphasize the fixating, and thus constraining nature of repetitive training. An integrative report takes up both of these findings and then tries to find some coherent reason, including some wild guesses sometimes, for the diversity. An example excerpt reads,

"Human beings can sometimes learn to be an amazingly skillful in a specific task. Also, human beings have a tendency to use some particular strategy in solving problems-they may opt for efficient ways of solving, or stick to some cost-effective strategy. This tendency often makes human beings effective problem solvers, particularly when they are solving the same or very similar problems, while it can cause confusion when they encounter a new situation where the acquired strategy is not effective anymore.

We can speculate that human beings might have evolved their problem solving strategies according to their needs in evolution, different strategies at different times. On the long course of time things were lost, which may reflect our weaknesses. Advantages and disadvantages are the head and the tail of the same coin. Human beings must have chosen the way in-between the trade-offs."

List-up repots, on the other hand, literally listed up all the studies contributed by the class members. These were exhaustive and meticulous reports, reflecting the hard work done by the students, though less efforts Figure 3: Figure 3. Number of notes visited during each study period for each report type were paid to integrate them. The self-centered reports never took off very far from the original topic each author had started the class. The students selected some studies relevant to their topic research and structured the reports around them. 
Figure 3 depicts the relationship between the types of final reports and the number of notes visited by the groups. The groups that produced the list-up type and the integrative type of reports had a higher tendency to visit created notes, particularly in the relation-finding and summary-writing phases. These activity patterns match the content and the quality of the reports, indicating that the activities ReCoNote could solicit in fact had the positive effects on the high performance of the students.

\section{Conclusion}

The data analyzed so far indicate that the note-sharing system with specific emphasis on relation making among the notes helped the students structure their learning materials on their own. Integrating classroom activities with the tool use is important, though this itself is a known fact. What we think we can contribute to the field of learning sciences is 1) that more emphasis should be and could be put on students' active role in structuring the learning materials by explicitly requesting the students to integrate them together, and 2) that such emphasis could be supported by an enriched type of note-sharing system.

\section{References}

Bereiter, C., \& Scardamalia, M. (1993). Surpassing ourselves. Chicago and La Salle, Illinois: Open Court.

Miyake, N. (1986) Constructive interaction and the iterative process of understanding, Cognitive Science, 10, 151177.

Miyake, N. (1996) Conditions for constructive interaction, Cognitive Studies: Bulletin of the Japanese cognitive Science Society, 3, 26-27.

Bell, P., Davis, E., \& Linn, M. (1995) The knowledge integration environment: Theory and design, CSCL '95, 1421.

Kirsh, D., \& Maglio, P. (1994) On distinguising epistemic from pragmatic action, Cognitive Science, 18, $513-549$.

Shirouzu, H., \& Miyake, N. (1999) Roles of cognitive externalization for joint problem solving, Proceedings of the 2nd International Conference on Cognitive Sciences, pp. 337-342.

\section{Acknowledgements}

This research was partially supported by The Special Research Aid to Inter-Departmental Collaboration by Chukyo University, 1996, Grant No. 964702, as well as by Grant-in-Aid for Scientific Research (C) by Ministry of Education, Science, Sports and Culture, Japan, Grant No. 09680380, 1997-1999. We thank all the participating students for their hard work. We are also grateful for the reviewers' comments given to the previous version of this manuscript. 